\title{
Putting Together a Global Effort
}

\author{
Joon Pio (Jp) Hong
}

Associate editor, Archives of Plastic Surgery

Department of Plastic Surgery, University of Ulsan Asan Medical Center, University of Ulsan College of Medicine, Seoul, Korea

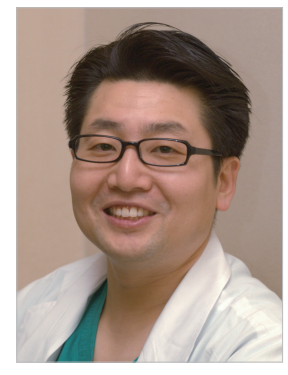

For as long as Archives of Plastic Surgery (Arch Plast Surg, APS) has been published, we have steadily increased the readership of the journal. This has been a combined effort on the part of the readers, authors, and editors of the journal. We continuously seek to improve the journal to bring new ideas and science to our readers. As part of this effort, we recently had our first global editorial board meeting during the Ninth Congress of the World Society for Reconstructive Microsurgery (WSRM) this June.

This meeting was held following the 'Publication for Microsurgery' session of the WSRM congress. Among the international editorial board members of APS, Bernard T. Lee (Harvard Medical School), Stefan O.P. Hofer (University of Toronto), Gautam Biswas (Tata Medical Center), and David W. Chang (University of Chicago) attended. Domestic members, including Yong-Ha Kim (Editor-in-Chief), Joon Pio Hong, Goo Hyun Mun, Hak Chang, Kun Hwang, Seung Suk Choi, So Young Lim, Seung Yong Song, and Tae Gon Kim, attended, and discussed the current status and future direction of APS (Fig. 1). Although APS is the official journal of the Korean Society of Plastic and Reconstructive Surgeons, it welcomes communications from around the world. APS aims to be the leading forum for communications regarding techniques related to Asian patients' needs. APS also embraces its identity as the leading plastic surgery journal in Asia, aiming to be the main forum for communication among the plastic surgery scholars and clinicians of the Asia-Pacific region and beyond, and the main voice presenting this group's technical innovations to an international audience. It is published 6 times per year and it is a peer-reviewed, open access journal that publishes articles in all fields of plastic and reconstructive surgery. Its open access status allows knowledge to be shared and disseminated more quickly, easily, and efficiently to our readers and colleagues.

During the meeting, the board recognized the need for further improvement and agreed to put more efforts into increasing the quality and readership of the journal. The impact of the journal has been steadily increasing, and APS is now listed in PubMed, PubMed Central, Google Scholar, SCOPUS, Embase, and KoreaMed. Citations of the papers of the journal have also been steadily increasing. The Scientific Journal Ranking (SJR) is a size-independent prestige indicator that ranks journals by their average prestige per article. It is based on the idea that "all citations are not created equal." The SJR is a measure of the scientific influence of journals that accounts for both the number of citations received by a journal and the importance or prestige of the journals where such citations come from. It measures the scientific influence of the average article in a journal, and thereby expresses how central to the global scientific discussion the average article of a journal is. The SJR for APS has increased from 0.429 (2013) to 0.711 (2015). The journal aims to be listed in SCIE soon. Hopefully, by increasing the exposure of the journal on social media and by conducting various annual meetings, awareness of the journal will continue to increase.

The attendees also discussed ways to promote the journal via e-mail or social media. However, the effectiveness of using social media was controversial because of the limited range of users.

APS will continue not charging for publications, which makes the journal unique and helps ensure objectivity in the publication process. In the effort to continuously increase the quality of the review process, multiple new initiatives such as recruiting more reviewers and evaluating reviewers will continue. We also 

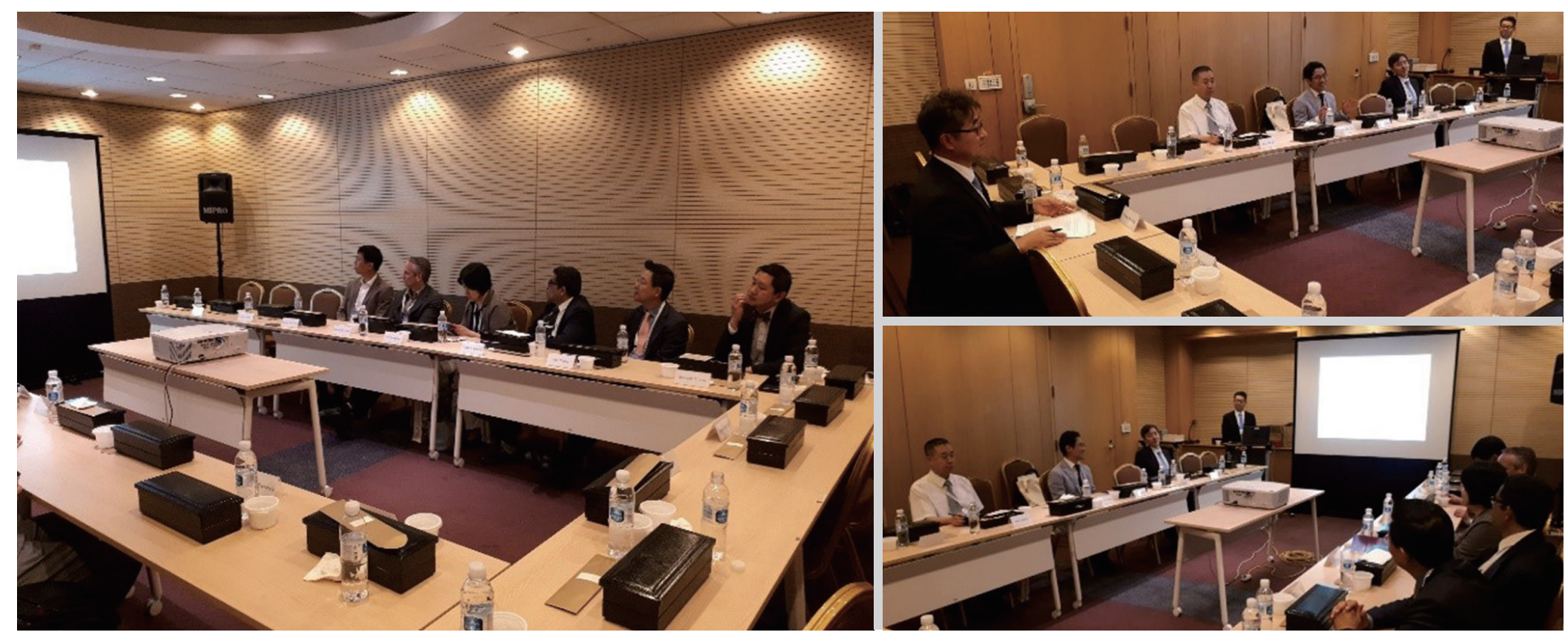

Fig. 1.

The first global editorial board meeting of Archives of Plastic Surgery was held on June 15, 2017, during the Ninth Congress of the World Society for Reconstructive Microsurgery.

hope to make the submission process more user-friendly.

The first global editorial board meeting was an important turning point for the journal, and the opinions gathered from this meeting will allow the journal to continue growing in a healthy manner.

On behalf of the editor-in-chief, Dr. Yong-Ha Kim, we thank the editorial board members, especially the international members, who took part in this meeting and who continue to support the journal by investing their time and knowledge.
Correspondence: Joon Pio (Jp) Hong

Department of Plastic Surgery, University of Ulsan Asan Medical Center, University of Ulsan College of Medicine, 88 Olympicro 43 gil, Songpa-gu, Seoul 05505, Korea

Tel: +82-2-3010-3600, Fax: +82-2-476-7475, E-mail: joonphong@amc.seoul.kr

No potential conflict of interest relevant to this article was reported.

Received: 30 Jun 2017 • Revised: 2 Jul 2017 • Accepted: 3 Jul 2017

pISSN: 2234-6163 • elSSN: 2234-6171

https://doi.org/10.5999/aps.2017.44.4.259 • Arch Plast Surg 2017;44:259-260 